\title{
Special Education 2000 Policy: Our Leaky Home?
}

\author{
Peter Coleman \\ President-Elect, NZPsS
}

\begin{abstract}
The Ministry of Education's special education policy (commonly referred to as SE2000) has been progressively implemented since 1996. Although it is a funding rather than a professional-practice policy, it has had some negative and unintended consequences for the practice of educational psychology, for special education and it is suggested, for education generally. This paper explores the development, implementation and adaptations of SE2000, and the practical outcomes for children with special education needs. Through day-to-day and perhaps unquestioned use by educators (e.g. we now comfortably talk about "ORS" and "SLS" pupils); SE2000 has become legitimised as a de facto diagnostic framework. It will be argued that it conforms rather more to a layperson's understandings of special education taxonomies with all of the distortions and misunderstandings that this creates, than to a scientifically rigorous framework. SE2000 is well overdue for a scholarly review but the Ministry of Education (and it must be acknowledged both major political parties) have been reluctant to authorise or accept the need for a functional analysis of the professional activities that are supported by the policy, and the corresponding outcomes of it. The fact that the number of adaptations and additions to SE2000 (often referred to as "Initiatives") has steadily grown over the years, suggests that the basic framework is inherently flawed. It will be argued that any attempt to validate such taxonomies is probably doomed to fail and that children would be better served by a needs-based rather than a categorybased funding arrangement.
\end{abstract}

\section{Position paper}

Keywords: Educational psychology, funding, policy SE2000

\section{INTRODUCTION}

This paper addresses one of the themes raised in three Psychology Aotearoa papers by Brown (2010), Coleman and Pine (2010) and Hornby (2010). It comments on the impact of policy, specifically Special Education 2000, on the professional practice of educational psychology and special education.
It is important to recognise that the current SE2000 policy is a funding policy, not a professional practice policy. However, that is not to say that a purely funding-oriented policy doesn't have (possibly unintended) implications for professional practice and as a consequence, implications for the meeting of the special needs of the pupils whom it is intended to serve. One very visible artefact of the policy is the day-to-day emphasis on funding which instead of being 'enabling' often functions more like a dowry, rather than providing an emphasis on the specific instructional accomplishments and needs of the child. Similarly, the 'currency' used in negotiating the enrolment of children with special needs in mainstream schools rather too often has become 'teacher aide hours', rather than a discussion of their individual needs. For example, the first questions often asked of parents who wish to enrol their child with special needs at their local school is "Is she/ he ORS (Ongoing Resourcing Scheme) funded?" and of supporting Ministry of Education: Special Education (MOE:SE) field-staff "Does s/he have teacher aide funding?" Secondly, although the policy was intended to achieve "a world class inclusive education system that provides learning opportunities of equal quality to all students" (Massey University College of Education, 1999, p. 5), it essentially entails a reactive, deficit and categorical response (i.e. according to the qualifying criteria for the components of SE2000). In other words, the policy represents the antithesis of inclusive education rather than a proactive, consultative and needs-based way of working with children with special needs by educational psychologists (and others) in schools.

This paper argues that SE2000 imposes a lay taxonomy of special education on us all, a taxonomy that has 'under-laps' (gaps in 'need' and service provision), 'overlaps' (duplication of need and service provision) and demarcation issues (e.g. access criteria, across-service protocols and review processes). At the individual level, the policy sometimes assumes that pupils clearly have or clearly do not have special needs (i.e. they are either eligible for ORS funding or not, rather like pregnancy or the flu), that special needs are discrete and do not interact (i.e. the pupil has communication, academic or behavioural needs but not all three - or more - needs) or that some 
needs do not warrant the involvement of special education professionals. Stunningly, psychologists who are employed within the Ministry of Education: Special Education (formerly Group Special Education) have absolutely no involvement in addressing the espoused Governmental goal of enhancing literacy and numeracy deficits and needs of pupils who are described as the twenty percent "tail of underachievement" (Report of the Education and Science Committee, 2008, p. 7) and who are disproportionally of Māori of Pacific Island ancestry. When one considers that descriptors of the core scope of educational psychology probably includes words like 'learning', 'instruction', 'pedagogy' and 'teaching', and that these are no longer within the functional scope of practice of educational psychologists employed within the public sector, we know that we have a problem. In short, SE2000 provides the context or environment in which educational psychologists practice and has a profound effect on with whom and equally significantly, how they work.

This paper will comment further on some of the other special education needs that appear to have been overlooked in the SE2000 policy (e.g. pupils with significant learning problems who are not ORS verified), pupils who present with challenging behaviours for whom the precursors are difficulties in accessing the curriculum (i.e. the current clients of the behaviour service whose academic needs are currently ignored whilst acknowledging that there will be exceptions), pupils with 'internalised' (e.g. anxiety, depression, social isolation) or mental health issues, and pupils who no longer receive service from educational psychologists (e.g. ORS funded pupils who are enrolled in special schools). There will again be, in the main, serendipitous exceptions to these exemplars. Other professional groups (e.g. Resource Teachers: Learning and Behaviour (RTLB), Resource Teachers of Literacy (RTLit) do some of the work that was previously undertaken by educational psychologists and, it is acknowledged, educational psychologists employed within the Ministry of Education (MOE) most often do good work. But SE2000 simply doesn't cater for 'special needs' being a multidimensional continuum, for these needs to extend to family and community issues and for the need in schools for systemic as well individual casework. It is encouraging that the Ministry of Education: Special Education is introducing a school-wide discipline initiative (known internationally as School-Wide Positive Behaviour Support (SWPBS) which may allow educational psychologists to work systemically within schools. This has the local acronym PB4L (Positive Behaviour for Learning) but as yet there is no indication that the 'learning' component will be a legitimate area of work for MOE-employed educational psychologists.
As a consequence of the SE2000 categorical framework, an excessive amount of time and resource is probably expended in establishing whether or not a child meets criteria for service under one or more of the components of the policy. Reynolds, Wang and Walberg (1987) estimated, for example, that internationally up to one half of the costs associated with educating a child with special education needs are taken up with the identification process. The extent to which this is true in the New Zealand context is unknown and presumably would vary across the funding categories of SE2000. If one considers the separate management structures for each major provider and funding category (e.g. MOE:SE, RTLB), the management processes within each subset of these within MOE:SE (e.g. ORS, Supplementary Learning Support (SLS), Behaviour Initiative, Communication, Assistive Technology, Interim Response Fund etc.) and reporting requirements, the percentage could be quite high indeed. This is probably just as true for the ORS verification and funding processes and for the internal MOE:SE referral and associated processes as for some of the other components of the policy. Such time and resources would probably be better spent in meeting the child's needs, something which clearly promoted the USA's 'No Child Left Behind' legislation and the corresponding 'Response to Intervention' model of assessment. This used to be known as needs-based assessment and intervention, and we need to return to it.

There is a dearth of research into the practical outcomes for children of SE2000 which is surprising given the professional practice emphasis for using evidence-based interventions in casework and teaching. Whilst there have been a significant number of evaluations, research papers and reviews of one or more components of SE2000, none of these (unless in passing) have demonstrated that any pupil in any school has received a service and made academic, personal or social gains that they would not have made if we didn't have SE2000. These research efforts, evaluations and reviews almost without exception have focused on the machinery (e.g. administration, management and governance) of the policy and the perceptions of parents, teachers, principals, Boards of Trustees and other stakeholders of its efficacy. This is not to say that such research, evaluations and reviews do not have a place; they obviously do. However, if we look at the chain of evidence for the efficacy of SE2000, one important component is missing; which children have benefited, how many and in what ways? Towards the end of this paper a research theme will be presented to counter this deficit under the 'high needs' targeted-funding components of SE2000 (e.g. Early Intervention, ORS, SLS,

Communication, Behaviour) and the unmet learning needs referred to above. 
A few clarifying statements might be useful here. It is fully accepted that those who had an involvement in designing and implementing SE2000 were well-intended and undoubtedly had the best of interests of children with special needs in mind. Both major political parties were, and remain, fully supportive of SE2000, and the current situation has evolved over a significant period of time rather than being attributable to any one decision. It is fully acknowledged that many children will have benefited from the significant amount of additional funding that has been provided since SE2000 was implemented and from the services that this has enabled. In particular, many children who have very high needs have clearly benefited and although there are problems with the ORS funding model (this is described in the body of this paper), it is fully accepted that many of these children are entitled to have their educational needs met throughout their school career.

However, SE2000 has been implemented under a curious mixture of the devolved self-management model of 'Tomorrows Schools' coupled with the corporate management model of the Ministry of Education: Special Education. This presents a degree of political and managerial decisionmaking which in previous years may have been regarded the province of professionals. At the most basic level this means that a decision on who gets access to what kind of special education service (and indeed the design of the overall diagnostic framework within which such decisions are made) and for how long, is as likely as not to reflect a management or policy decision rather than a professional decision. This has always been the case where public money is involved but perhaps never quite so obviously. As a result, MOE: SE professional staff are probably not as responsive to the needs of schools as perhaps they could and should be.

\section{OVERVIEW OF SPECIAL EDUCATION 2000 POLICY FRAMEWORK AND ADAPTATIONS}

This funding model is usually presented as a triangle with the $1 \%$ of the school population having the highest needs attracting ORS funding, another $1 \%$ attracting specialist communication services (i.e. Speech Language Therapy input from MOE:SE) and a further $1 \%$ with severe behavioural issues receiving service from a psychologist or special education adviser, also from MOE:SE. Approximately half of the children who are verified as having high needs attend regular schools and receive specialist services (e.g. speech language therapy, occupational therapy, physiotherapy or have psychologist or special education adviser involvement) from MOE:SE, which is their ORS 'fund-holder'. Except for a relatively small number of children for whom their local school consortium is their fund-holder, all of the other verified pupils receive specialist services from the special school (for intellectually or physically disabled), special unit (for physically disabled), resource centre or high school 'learning unit' in which they are enrolled. The group of four to six percent of school-aged children under the triangle, who are described as having moderate rather than high needs, are catered for by RTLB, the Special Education Grant (SEG) and the Moderate Physical Needs Contract.

In addition, MOE:SE provides a multidisciplinary Early Intervention Service for preschool children and the psychologists who work in this area have arguably been the least detrimentally affected by the policy. We will now look in greater detail to each of these main SE2000 funding strands (including school's SEG) and some of the minor ones.

\section{ORRS Funding}

Pupils with an ongoing high level of need (due to, for example, a severe or profound intellectual or a serious physical or sensory disability) are directly resourced through the Ongoing Resourcing Scheme (ORS) as introduced above. This was previously known as 'ORRS' when there was a reviewable component in which the funding lasted until the end of the year of verification plus three years, after which a further application was necessary. The reviewable component was dropped in April 2011, and pupils who are currently 'verified' as being eligible for ORS funding, will receive this until they leave school.

To meet the criteria for verification pupils must have extreme or severe difficulties in (one or more of) learning, hearing, vision, mobility, language use/social communication or moderate or high difficulties with learning arising from (any two of) hearing, vision, mobility and language use/ communication. Such pupils are verified as being eligible for either the Reviewable Resourcing Scheme or the Ongoing Resourcing Scheme under two levels of support ('high' including combined moderate ongoing needs and 'very high' special needs), by a team of Ministry of Education employed 'Verifiers'. The compulsory sector application form requires the pupil's teachers provide information of functional oral language skills, written language skills, mathematics, science, technology, social studies, health and physical education skills, communication skills, work and study skills, problem-solving skills, information skills, self management skills, social and cooperative skills, and physical skills. Pupils are deemed to be eligible if they meet at least one of nine criteria, namely: 
- Needs total adaptation of all curriculum content.

- Needs special assistance to engage in all face-to-face communications (e.g. rely on signing, a communicator after cochlear implant or on Braille).

- Needs specialist 1:1 intervention at least weekly and/or specialist monitoring at least once per month together with daily special education support for help with mobility and positioning or personal care.

- Needs specialist 1:1 intervention at least weekly and/or specialist monitoring at least once per month together with daily special education support for help with needs arising from a severe disorder of both language use and appropriate social communication.

- Needs significant adaptation of almost all curriculum content.

- Needs specialist teacher contact time of at least $1 / 2$ day per week (i.e. from a teacher with specialist skills in deaf education or a teacher with specialist skills in visual disability) to access the curriculum.

- Need specialist 1:1 intervention on an average of once per month and/or specialist monitoring on an average of once per term together with daily special education support provided by others for help with mobility and positioning or personal care.

- Needs specialist 1:1 intervention on an average of once per month or specialist monitoring on an average of once per term together with daily special education support provided by others with needs arising from a severe disorder of both language use and appropriate social communication.

- Students with combined moderate ongoing needs (requiring significant adaptation of most curriculum content, specialist teacher intervention and monitoring to assist with an ongoing moderate hearing impairment, specialist teacher intervention and monitoring to assist with ongoing moderate vision impairment, specialist intervention and monitoring to assist with ongoing moderate physical needs, specialist intervention and monitoring to assist with an ongoing moderate disorder of both language use and appropriate social communication).

Obtaining verification for a pupil simply because of their learning and instructional needs is infrequent and unlikely. For example, in the absence of a physical or sensory disability, pupils with functional language much beyond three to four years or academic skills beyond Level 2 of the national curriculum, no matter what their chronological age, are unlikely to be verified. In contrast, pupil's having significant self-care and physical or sensory disability issues are much more likely to be eligible for verification. The school of a pupil who has been 'verified' as having 'high needs' receives a staffing allocation of 0.1 (half day) additional teacher time and one who has been verified as having 'very high' needs will be allocated 0.2 (one day) additional teacher time per week. Their school also receives funding each term to cover the cost of small items for a 'verified' pupil, such as computer software, extra-size pens, Braille machine paper, laminating pouches etc. Students with 'very high' needs receive a higher sum. Specialist services such as physiotherapy, occupational therapy and speech-language therapy are provided on the basis of each student's needs. These specialists and therapists are employed by and available through the MOE:SE where the Ministry is the fund-holder. Where a specialist service provider (e.g. Special School or consortium of schools) holds the funds for a student, they are responsible for the provision of specialist services not MOE:SE. Finally, the pupil will receive a variable level of teacher's aide support as determined by a review and moderation process; this comes from the pooled funding for 20 or more verified pupils and is known colloquially as 'over's and unders'.

A number of changes to the ORRS (now ORS) scheme were made after the 1997 trialling and include:

- The introduction in 1998 of transitional resourcing through ORRS (also known as Ongoing and Transitional Resourcing Scheme) for children aged 5 to 7 years old, whose long-term educational needs were still unclear.

- The extension of the ORRS scheme in 1999 by the addition of the 'combined moderate needs' criteria above, chiefly to accommodate pupils diagnosed with Pervasive Developmental Delay or Asperger's Syndrome. This additional criteria remains in ORS.

- In 2000 the Reviewable Resourcing Scheme (RRS) replaced the Transitional Resourcing Scheme.

- An increase in funding for ORRS (now ORS) funded students in rural schools.

- As from 2010 an 'ORRS Extension' was created to help 400 students who also just missed out on verification. The ORRS Extension was created as an interim approach to expand ORRS while the Government carried out a now-completed review of Special Education services and support. These students will be on the 
programme until they finish school or until the end of the year they turn 18.

- In early 2011 the Reviewable Resourcing Scheme is removed and the ORRS acronym is shortened to ORS or 'Ongoing Resourcing Scheme'.

- In recent months, and following feedback presented in "The Review of Special Education; Public Response Summary" (MOE, 2010), the Government has announced in "Success For All - Every School, Every Child", another extension of ORS funding to an additional 1100 school-aged pupils and additional support to another 1000 pupils in their first three years of schooling. It also made some other changes, but change to the overall SE2000 structure is clearly not part of this.

\section{Special Education Grant}

The funding formula for the Special Needs Grants (SEG) provided to all schools is a combination of the roll number and a dollar sum taken from a table of decile rankings. The decile is simply a statistical device to indicate the social-economic status of the population served by the school and is taken from census data. The Targeted Funding for Educational Achievement (TFEA) is another attempt to compensate for the economic and cultural 'capital' that pupils from low socio-economic schools lack, and together with SEG funding, acknowledges that low socio-economic schools are likely to have a disproportionate number of pupils with mild and moderate special needs enrolled. SEG funding is used in a variety of ways by schools including paying for teacher aides and a special needs coordinator.

\section{Other Components of SE2000}

The other major components of the Special Education 2000 policy include:

- The 'Speech Language Initiative' provides specialist support for students with severe communication needs through MOE:SE.

- The 'Serious Behaviour Initiative' provides specialist support and guidance to pupils displaying severe and challenging behaviour through MOE:SE.

- The Regional Hospital Health Schools provides teachers and specialist support for students who are in hospital, convalescing at home or who are in the process of returning to school.

- The Moderate Hearing Impairment Contract provides four regional coordinators to supervise the itinerant teachers of the deaf who locally support students with moderate hearing impairment. MOE:SE also employs advisers for deaf children.
- The Moderate Vision Impairment Contract provides itinerant teachers of vision impairment who locally support students with moderate vision impairment.

- RTLB provide services for students with moderate learning and/or behaviour difficulties.

- The Assistive Technology fund is available for pupils who need technological support (e.g. a computer) in order to access the curriculum.

Other changes to the original SE2000 framework in addition to the ORRS/ORS changes noted above include:

- The allocation of 'Transition Bridging Funding' to individual schools on behalf of students with S.9 Agreements who have not/were not verified for ORRS; this funding was in response to Quality Public Education Consortium's successful High Court appeal and has now expired.

- The allocation of 'Learning Support Funding' to RTLB clusters to enable them to provide assistance to schools on a needs basis to support their students with moderate needs.

- The temporary devolution of funding for and the management of transport to fundholders.

- The creation of 'Facilitator' positions within the MOE to conciliate between parents and schools, in typically, enrolment and funding issues. However these positions were disestablished in 2008.

- The Moderate Physical Needs Contract to provide Occupational Therapy and Physiotherapy services to students with moderate physical needs. This was a three year package of support and research for students with physical disabilities and has since been reviewed.

- Schools High Health Needs Fund which provides resourcing for teacher aide (paraprofessional) care and supervision for students with high health needs so that they can attend school safely.

- Supplementary Learning Support that was intended to provide 1500 students nationally who are already receiving support from one or more SE2000 initiatives (and have "just missed out on ORRS") with .1 FTE teacher and 45 hours of specialist input. This has recently been extended.

- An inter-sectoral (i.e. health, education, welfare including social development) High and Complex Needs initiative for children aged 2 to 7 years who have severe and challenging behaviour was first trailed in Auckland, Manawatu and Dunedin in 2004 
and has been extended to other centres and up to the age of 17 , and in some circumstances, 21 years. This has been designed in partnership with 'Strengthening Families' and is intended to intervene early with children from 'high risk' families.

- An Enhanced Programme Fund (initiated in 2002 following the Wylie Report) to supplement the SEG in schools (the socalled magnet schools) which attract a disproportionate number of pupils with moderate special education needs.

- An Interim Response Fund which provides a terms funding to a school (usually to employ a teacher's aide) to maintain the enrolment of pupils with challenging behaviours until MOE:SE staff became more fully involved.

- The Government has recently announced as part of "Success For All - Every School, Every Child" a restructuring the RTLB Service so that each Cluster employs 30 RTLB rather than the original 8 to 10 , and a part-time manager and professional advisor. This transformation of the RTLB Service is expected to be implemented in 2012.

\section{RESEARCH INTO SE2000}

Early formative reviews of the Special Education 2000 Policy were provided by Wylie (2000) and the Massey University College of Education (2002) Phases 1 to 3 evaluations.

\section{The Wylie Report}

The 'Wylie' review received over 1000 submissions and included meetings with organisations and interest groups, and some site visits. She concluded that "The Special Education 2000 policy has expanded the number of students receiving special needs support to 5.5 percent of the school population [but that] the division of the policy into a number of separate initiatives and funding pools has made it hard to offer students, parents, and schools, the seamless, integrated service which works best for students with special needs" (p. 8). However, the number of special education 'initiatives' has more than doubled since the Wylie report and so the services available under SE2000 are even more fragmented. She also concluded that the ORRS funding model worked best for Special Schools but didn't work particularly well for Specialist Education Services (SES) which was subsequently restructured as Group Special Education (GSE) and is now known as Ministry of Education: Special Education (MOE:SE) who didn't have the economies of scale enjoyed by special schools and who had to provide services in rural or remote areas and, as could be added, difficult to staff areas.
Wylie noted that the Severe Behaviour Initiative had the lowest satisfaction rate of the main SE2000 initiatives. She pointed out that "SES staff also felt unable to work more proactively and systematically (i.e. systemically) with schools to develop an environment in which behaviour problems were reduced" (p. 58). She reiterated that a significant proportion of pupils on psychologists' and special education advisors' caseloads (20-30 percent eighteen months after the introduction of the initiative) had ongoing or chronic needs for support in relation to their problem behaviour (e.g. family and mental health issues) and this prevented many teams from accepting more referrals or the initiative meeting the then annual target of providing service to 7,000 students.

Wylie also found that about one half of schools thought that they could meet the needs of the pupils described as having moderate needs by a combination of their SEG and the involvement of the RTLB. A large number of recommendations were made to address these and other issues that arose in the review.

\section{The Massey University Summary Reports Phase 1, 2 and 3, Monitoring and Evaluation of The SE 2000 Policy and 2002 Final Report}

This longitudinal evaluation addressed 126 questions that were initially provided by the Ministry of Education.

The methodology for this evaluation included yearly questionnaires to schools, site visits and interviews in four SES regions including six case studies of selected students. It is very important to note that the data that informed the final evaluation was (apart from the six case studies), the opinions of many stakeholders on the effectiveness of the initiative, rather than hard process and outcome data.

In general terms, the MOE wanted to know how SE2000 was affecting students, parents, schools and providers. The research team noted that:

in order to do this, the study focused on the perceptions of those involved in implementing the policy and experiencing its effects.

Research data were collected from over 8000 educators over three years. Schools, Early Childhood centres and Kura Kaupapa Maori were surveyed nationally. Case studies were undertaken in the Severe Behaviour Initiative, Regional Hospital Health Schools and Residential Special Schools. Principals, teachers, teacher aides, parents and providers were interviewed and state-funded residential special schools were also visited

(Massey University College of Education, 2002, p. 7). 
Sixty-one of the initial 126 questions were addressed in Phase 1 of the study and baseline data collected for the following two phases. This data included a national survey of schools and early childhood facilities supplemented by site visits to four geographical areas and to six residential schools, parent forums in four centres and interviews of SES group managers. Phase 2 of the study reported on initiatives for students with high or very high needs (i.e. ORRS, Behaviour and Communication), initiatives for students with moderate needs (i.e. SEG, moderate physical and moderate sensory needs) and five other issues or provisions. Data in this phase came from an analysis of a national survey, interviews of teachers from 36 early childhood centre associations, case studies from six residential special schools, 'Serious Behaviour Initiative' cases from four SES areas and phone interviews of 246 parents. Overall, the highest levels of satisfaction were reported for moderate needs SEG and RTLB and for ORRS and the lowest for the Serious Behaviour Initiative. The findings on the then just introduced (moderate) RTLB service was presented in a later Phase 3 report. This reported increasing levels of satisfaction for the very high and high initiatives and for SEG and RTLB, but levels of satisfaction for the behaviour initiative remained low.

\section{Related Research and Developments}

Following Wylie's finding that the access of children with physical disabilities to physiotherapy and occupational therapy in schools was limited, in 2003 the Ministry of Education commissioned two descriptive research reports (Clark et al., 2007; Ministry of Education, 2007) to inform policy, planning and practice. One of these used quantitative data obtained from the compulsory school sector whilst the other used descriptive case studies to illustrate the day-to-day challenges and achievements of these pupils. This resulted in the development of the Moderate Physical Needs Contract cited above.

Special Education resourcing in general was the subject of an independent survey (Ward et al., 2009) which was undertaken in order to inform the Government about the level of special education resources received by schools and the allocation of special education resources to students. Extensive data were collected at three levels including 653 teacher and parent case studies, and the overall finding was the perceived importance of teacheraide time and quality full time teacher support for pupils with special education needs; these accounted for much of the expenditure from all of the funding streams. Although satisfaction was generally expressed about the progress made with these 653 students, there was only a weak correlation with the objective data of the progress made by these students. About one half of teachers and parents were satisfied with the available levels of resourcing.

The Ministry of Education has also from time to time funded research proposals whose scope is wider than the above two projects, but very relevant to special education. In this section two of these will be listed and briefly described. A report by McMenamin et al. (2004) assessed how well national curriculum policy in New Zealand articulated learning outcomes for students who have special education needs. They reviewed national and international literature relating to curriculum policy and special education, and included interviews with five schools which supported students with special education needs. A characteristic of the literature reviewed was the dearth of studies that have explored the link between curriculum policy and the impacts of such policy on outcomes for students. Much of that reviewed regarding students with special educational needs focused on practical aspects of provision, particularly processes to support participation in educational settings rather than the outcomes of educational participation per se, and on structural arrangements, particularly resourcing. The other significant gap in the literature was an investigation of the outcomes for Māori and Pasifika students who also have special educational needs.

The lack of research evaluating the effectiveness of different curriculum policies meant that this report focused on descriptive data only. No benefits or implications of vertical versus horizontal provision of curriculum policy or learning outcomes were identified, nor did the school personnel participating in the interviews have strong feelings about these options. There was some support amongst the interviewees for the development of a foundational achievement level for students who may not progress to Level 1 learning objectives, and indeed was sometimes found within some schools. The usefulness of current national curriculum documents, particularly the New Zealand Curriculum Framework and Te Whāriki. Early Childhood Curriculum was perceived very differently across schools. In all cases, the Individual Educational Programme (IEP) formed the cornerstone of curriculum planning and reporting for students with special educational needs. For students with moderately high to high needs, the participating interviewees identified functional curriculum outcomes (principally life-skills) as particularly important. As with the literature overall, investigation of the transition from preschool to school for students with special educational needs was found to focus on processes and resourcing, rather than on the relationship between the transition and specified curriculum outcomes. 
The well-known longitudinal EEPiSE project (Special Education Division, 2004), to paraphrase, was aimed to develop teacher knowledge and share ideas on how to support learners who require significant adaptation to the curriculum content in regular schools, school-based classes for students with special education needs, Kura Kaupapa Māori and special schools. The project included a literature review, a pilot study (involving Helen Timperley, Patricia O'Brien, Mere Berryman and others), and a programme of longitudinal research and professional learning and development involving 49 schools across the country. In terms of professional development, teachers emphasised the need for professional learning to be situated within the context of their school for it to be effective and sustainable. The relationship between whānau and the school was seen as the key ingredient for enhancing learning, social and cultural outcomes for all students in the Kura Kaupapa Māori settings.

Five key characteristics for effective professional development and learning were identified in the project as:

- Professional learning opportunities must be based on immediate needs and build upon existing knowledge.

- Teachers become facilitators and begin owning the process of professional learning and development.

- Support to meet the needs of diverse learners is required.

- Support for teachers needs to be built into school-wide planning for raising student achievement.

- Collaborative planning leads to goals that require ongoing monitoring, adaptation and review.

Using the findings from the literature review and pilot study during 2005 and the first half of 2006, the focus was on identifying, exploring and supporting pedagogy and practices which are most effective in maximising learning, social and cultural outcomes for students with special educational needs who require significant adaptation to the curriculum. Schools chose to take part in either developing professional learning communities (in 24 schools) or in action research, professional learning and development (in 25 tikanga Māori schools). In June 2006, many schools took part in a series of regional symposia which marked the formal conclusion of the EEPiSE programme.

A special issue of Kairaranga brought together an array of articles based on schools' presentations, alongside accounts from the keynote speakers and the EEPiSE project team. A useful summative resource is provided in Weaving Evidence, Inquiry and Standards to Build Better Schools (Timperley
\& Parr, 2010). It is also important to record the research undertaken by the Massey University 'Centre of Excellence for Research in Inclusive Education' (e.g. by Bevan-Brown, Mentis, Bourke, Annan and others). Unfortunately educational psychologists employed within MOE:SE have had little or no involvement with either of these multifaceted projects, which represents, it is suggested and repeated elsewhere, a distinct loss of opportunity for the dissemination of professionalpractice knowledge beyond the schools and teachers who were directly involved.

\section{REVIEWS OF TARGETED HI-NEEDS FUNDING}

\section{Ongoing Resource Scheme Funding}

The 2005(a) Education Review Office (ERO) review of ORRS found that two thirds of schools were using the funding effectively but that one in six was not. The subsequent June 2010 ERO reported on how well schools included and catered for pupils with high needs (i.e. ORRS funded) pupils. About one half of the schools reviewed demonstrated mostly inclusive practices marked firstly by ethical standards and leadership that built the culture of an inclusive school, secondly by well-organised systems, effective teamwork and constructive relationships that identified and supported students with high needs, and thirdly, by innovative and flexible practices that managed the complex and unique challenges related to the education of children with high needs. Thirty percent of the schools had some inclusive practices and twenty percent had few inclusive practices. The report stated (Education Review Office, 2010a, p. 1) that:

The key question that emerges from this review is how can more schools become better at including students with high needs? Schools invest in various professional development courses that provide specialist knowledge to teachers and support staff. Similarly, much of the professional support available from MOE:SE and Resource Teachers: Learning and Behaviour (RTLB) is aimed at supporting the inclusion of individual students. More can be done to use school-wide professional learning and development processes to make schools more inclusive.

The report recommended that as part of the Special Education Review, the MOE should consider:

how effective mainstream schools, special schools, Group Special Education, Resource Teachers: Learning and Behaviour can work together to improve the level of inclusion in New Zealand schools

(Education Review Office, 2010, p. 28).

Although funding played a part, the report found that the quality of leadership and the extent to which the schools could adopt a specialised 
pedagogy for high needs student was more important.

The recent announcements from the Associate Minister of Education reflected some of these recommendations, set a target of eighty percent of all schools having fully inclusive practices by 2014 in addition to the expansion of ORS funding as noted above, as was also prefaced in the last budget.

\section{Supplementary Learning Support}

SLS is a special education initiative designed to provide additional support to students with ongoing significant educational needs who have "missed out" support under the Ongoing and Reviewable Resourcing Schemes (ORRS). This support is in the form of 0.1 FTTE of a designated Learning Support Teacher and access to MOE:SE specialist support staff.

The effectiveness of SLS has been reviewed by the Ministry of Education (2006) which used an utilisation-focused approach. The study found that the initiative had achieved an equitable allocation of resource although finding appropriate staff for Kura Kaupapa schools was an issue, the itinerant Learning Support Teachers understood and developed their role, collaboration with school staff was occurring and that improved school attendance and participation by students was beginning to become evident. The evaluation is of particular interest because possibly uniquely, it included six informative 'outcome' case studies in addition to interviews with stakeholders and a questionnaire for a sample of SLS Learning Support Teachers.

\section{REVIEWS OF THE RTLB SERVICE}

RTLB service began in 1999 to assist schools and teachers in achieving the best learning outcomes for their students who have moderate special education needs. RTLB complete an Annual Report at the end of each year which asks for information about the schools and students they worked with during the year and the nature of their work. An early monograph (Research and Evaluation Unit, 2003) detailed the results from the 2001 Annual Reports and provided an overview of the work undertaken by RTLB during that year.

The Education Review Office report of 2004 was generally critical of the management and governance of RTLB clusters, finding little evidence of outcomes for their clients (particularly of Māori pupils), that some RTLB had been 'captured' by their school or principal, and that others were inappropriately working with ORRS verified pupils. The Ministry of Education responded by publishing the RTLB Toolkit (2007) and creating three national advisory positions. Part 1 of the Toolkit provided an introduction to RTLB and to Policy, and Part 2 contained chapters on Cluster Management, Staff Management, Staff Performance Management, Funding and Administration, Planning and Reporting, Professional Practice and finally, Service Provision. Significantly, for the current paper, there is no emphasis on professional practice beyond access and eligibility for service criteria and recommendations on referral, intervention, recording and reporting and review processes.

However, the subsequent 2009 Education Review Office review found that little had changed in governance and management following the previous review and publication of the Toolkit. They found that just under a half of RTLB clusters were well-governed and managed (those that were had strong leadership) and just over one half were not well-governed or managed. The review then asked whether a larger "economy of scale" (i.e. reduction in the number of clusters and a more centralised management) would ensure "a more cohesive and consistent approach to service". The Minister of Education's presentation at the New Plymouth RTLB 2010 annual conference implied that this suggestion would be enacted in 2012.

\section{REVIEWS OF OTHER COMPONENTS OF SE2000}

\section{Activity/Alterative Education Centres}

Activity Centres or as they are now known 'Alternative Education (AE) Centres' cater for 3500 pupils nationally aged 14 and above who have been alienated (and often excluded or expelled) from secondary education and the centres are attached to a local high school for administrative purposes. A sample of six AE sites were recently reviewed by the Education Review Office (2009) who found that the quality of the educational programmes and resources was sound (this often included The Correspondence School materials) and most emphasised literacy and numeracy skills. Forty-four percent of pupils returned to mainstream education, but some moved directly on to community training or employment. The review concluded that AEs provided an appropriate alternative (and a 'safety valve') for students who struggle in mainstream settings.

A subsequent report (Education Review Office, 2010b) described the critical factors underpinning good practices as:

- The quality of the relationships between staff and students.

- The use of a curriculum that matched the individual needs of students.

- The passionate and compassionate approach of Alternative Education staff. 
- The ability of staff to have students aspire for a more positive future for themselves.

- An ability to address the wide range of social and educational needs of students.

- The leadership and teamwork of Alternative Education providers.

- The relationships with schools.

- The relationships with whānau/families.

\section{Special Education Grant}

The Education Review Office (2005b) review highlighted concerns about school's 'over-use' of the grant to fund literacy development at a cost to, for example, pupils with physical, social-emotional needs and other needs, to 'top up' teacher-aide support for ORRS-funded pupils and pupils receiving a behavioural service from MOE:SE.

\section{Enhanced Programme Fund}

The Enhanced Programme Funding (EPF) followed from the Wylie Report and was designed to target resources to schools that attract a disproportionate number of moderate special education needs. EPF advisors were appointed in 2003 and an improved policy statement was prepared in 2005. It was evaluated by Gray Matter Research Ltd (2006) which provided formative feedback on the implementation process and conducted 17 case studies. They concluded that although schools spent the fund to the benefit of students with moderate special education needs, it was not possible to establish whether or not the three underlying policy goals (viz. rewarding 'magnet' schools, these schools enhancing their existing programmes, and developing their capability to meet the needs of this group of students) was met.

\section{Research That Is Now Needed}

A recent paper by Sigafoos et al. (2010) endeavoured to evaluate the efficiency and effectiveness of various models of special education funding. Whilst inconclusive (in practice, many of the models are mixed and their application to some of the SE2000 components is not clear), this has provided a framework for describing the basic characteristics of popular models. These as defined (with possible New Zealand examples) are:

- discretionary funding or the "provision of additional funding or a certain percentage" (p. 20)

- categorical funding (e.g. ORRS and Moderate Physical Needs Contract) or "a set amount of additional funding for each student with a disability" (p. 27)

- voucher programmes or "direct public payment to parents to cover their child's public or private school costs" (p. 27) moderated by the child's (e.g. level of disability) and the parent's characteristics (e.g. income) as defined

- census-based funding

- cost-based approach (e.g. High and Complex Needs) and to which perhaps could be added

- compensatory funding (e.g. Targeted Funding for Educational Achievement and Enhanced Programme Fund for 'magnet' schools).

However, the focus of this paper is more on 'what' is being funded and the practical outcomes of this for children than the particular funding mechanism. Most of the research and reviews that have been undertaken on the components of SE2000 are at the system, management and governance level or primarily report the perceptions of effectiveness by the stakeholders and include very little, if any, actual pupil outcome-data. The closest example to the latter provided in this paper is the "utilisation-focused" review of Supplementary Learning Support (Ministry of Education, 2006, p. 16) noted above and to a lesser extent the small-sample case studies of the Massey University (2002) evaluation of SE2000, Clark et al. (2007), the Ministry of Education (2007) and Ward et al. (2009). It is a puzzle why the MOE is apparently disinterested in discovering what the practical outcomes of its own policies (e.g. SE2000) and practices actually are for the intended recipients.

Research into the outcomes of targeted and specialist services funding therefore needs to be undertaken. (As argued elsewhere this would be best done by MOE:SE professional staff rather than by external contractors. It would serve a formative function for the work of educational psychologists, assist in refining their professional practice and acknowledge their traditional roles as scientist-practitioners). In essence, this requires an ongoing analysis of the functional outcomes for a sample of clients of MOE:SE and RTLB, in effect completing the chain of evidence for the efficacy of these components of special education policy. The Ministry of Education (2006) evaluation of Supplementary Learning Support used a very similar 'utilisation-focused' approach which begins with the premise that evaluations should be judged by their utility and actual use. This suggests that researchers should design an evaluation with careful consideration also of how everything that is done from beginning to end will affect use and outcomes. It is very similar to the approach described as 'backward mapping' by a prominent researcher in school reform, Richard Elmore (2005). 
An immediate problem is that educational psychologists, despite being registered as 'health providers', do not have access to an accredited ethics committee. Whilst the MOE has recently launched an 'Ethics Advisory Service', this clearly has a managerial advisory and gatekeeping function rather than providing ethical approval for research by field staff. Researchers who are affiliated to a university have access to a university ethics committee and psychologists who wish to undertake research into physical health, mental health or disability issues have access to their local Health and Disability Ethics Committee. Educational Psychologists employed by the MOE are, as a consequence, subject to a double jeopardy; that of either undertaking research without the necessary ethical approval, or of providing a therapy or intervention for which they are unable to obtain the necessary evidence. This is an unaddressed and serious issue which provides another example of the unintended outcomes of policy. A further question is whether or not the universities have been too compromised by their receipt of research contracts and grants from the MOE, to undertake a critique of Ministry policy and practices.

It is very much in the interests of university research teams to take note of professional practice issues for psychologists who work in the education sector if the outcomes of their research efforts are to be implemented and disseminated beyond the settings in which they were derived. If their functional scope of practice wasn't so restricted by the SE2000 policy, practicing educational psychologists would be in a unique position to disseminate, for example, the evidence-based practices for teaching literacy and numeracy skills. That they are not, and do not, may in part explain the plethora of non-evidenced based 'alternative' and 'complementary' educational therapies currently being promoted within our schools. Similarly, universities who are planning or reviewing their training programmes for educational psychologists should be very concerned about the restrictive context in which their students are to be supervised and possibly employed after their graduation.

\section{Specific Recommendations for Research}

There is a pressing need for research into the processes and outcomes of the work of MOE:SE, which is the primary support service for pupils who are taught in inclusive settings. Readers might like to reflect on the promise of SE2000 which was to provide a "world class inclusive education system" (Massey University College of Education, 1999, p. 5) and note that unlike, for example, Special Schools and the RTLB Service, MOE:SE is not subject to Educational Review Office audit.
There would, therefore, seem to be a need for a functional analysis of the MOE:SE work - ideally undertaken by practitioners - with pupils who have been verified as eligible for ORS funding under:

- Criteria 1 (needs total adaptation of all curriculum content);

- Criteria 5 (needs significant adaptation of almost all curriculum content);

- Criteria 8 (needs specialist 1:1 intervention/ specialist monitoring/special education support for needs arising from a severe disorder of both language use and appropriate social communication), and

- Criteria 9 (combined moderate needs).

This might reveal subtle and unplanned consequences of the SE2000 funding policy (e.g. the amount of time that MOE:SE psychologists and special education advisors expend in funding application, negotiation and 'moderation' processes in comparison to curriculum assessment, analysis, planning and intervention and monitoring processes) in addition to, for example, the acknowledged increase in the number of paraprofessionals delivering a special education service to high needs pupils and the growth in the rolls of special schools (McMenamin, 2009), at least in the Auckland area. One way of achieving this might be to look within the pupil's IEPs for evidence that specialist support translated into 'school' processes with curriculum outcomes (as opposed to medical/therapeutic treatment), as it seemed reasonable to assume that ORS funding has an educative as well as a personal-care purpose. Similar ongoing research should also be undertaken with a sample of pupils receiving Supplementary Learning Support funding. Further, it seems that the ORS application document for the school sector has not been modified to align with the five Key Competencies of the revised New Zealand Curriculum (Ministry of Education, 2007a) so this too needs attention.

A functional analysis of casework - again preferably undertaken by practitioners - within a sample of pupils who receive assistance from the MOE:SE behaviour service could be done using their 'service pathway' (access, engagement, assessment, intervention, evaluation and review) or the 'Effective Intervention for Challenging Behaviour' assessment and intervention model currently utilised by MOE:SE. Such an analysis was undertaken in the unpublished 'Behaviour Research Project' (Coleman, 2005) using the preceding, but very similar, multi-element assessment and intervention framework. Of particular interest would be the interaction between each pupil's challenging behaviour and their extant learning problems, in addition to family dysfunction, risk issues and mental 
health issues, etc. As a reasonable guess at least fifty percent of pupils who are referred for a behavioural intervention are also failing academically, yet this is not a focus of MOE:SE behaviour support teams. As noted in a preceding section of this paper, there is perhaps some hope of a change within the recently announced schoolwide Positive Behaviour For Learning (PB4L) initiative and the teacher-training component of the Incredible Years (Webster-Stratton, 1999) programme.

The PB4L framework has been adapted from the evidence-based "School Wide Positive Behavioral Support" (or SWPBS) work of Sugai, Horner, Colvin, Sailor and others (see www.pbis. org). However, as noted by Don Brown (personal communication, 30/07/10) "New practices emerge and new ideas are developed in any profession. They should show in practice as a general pattern as practitioners take them up, not as initiatives for selected schools, centrally chosen and managed". It is ironic that this kind of school-wide intervention (one example is 'Staff Sharing' which was based on the work of Glasser and developed and implemented in Auckland more than 25 years ago by Dinah Gill), couldn't be maintained after the introduction of SE2000, and is now being reintroduced as a MOE initiative.

Parallel research with pupils receiving a communication service from MOE:SE (i.e. a systemic analysis of language delay, language disorder, developmental or intellectual delay and academic delay, relevant ecological variables and the interaction between these and service provision) or with clients of the MOE:SE Early Intervention Teams (e.g. a systemic analysis of developmental delay, attachment disorders, the development of antisocial behaviours, relevant ecological variables and the interaction between these and service provision) might also be very revealing.

A related and interesting research question relates to those pupils who are not verified or otherwise clients of MOE:SE (i.e. are not behaviourally challenging and have age-appropriate language skills), but who have chronic academic and learning problems. Just who is providing a special education assessment and intervention service to these pupils and what is the nature of this service? Some of these pupils might be eligible for Supplementary Learning Support funding and receive service from RTLB and RTLits, but the practical effects of this have yet to be evaluated. It is of interest that following a recent ERO review (Education Review Office, 2009) the Minister of Education announced the appointment of '50 experts' to help schools develop better processes of assessment, planning and teaching in early reading and writing skills. Yet, as noted in the above example, this is precisely the kind of systems level work that educational psychologists were involved in prior to the implementation of SE2000!

The other stream of evidence that is visibly lacking is research into the effectiveness of implementation of the components of SE2000, particularly the individually targeted components, for example, the last two 'behaviour initiatives'. We are all aware that there is a chasm between the research evidence for what should work and the efficacy of this in practice. Often it is not the intervention per se that is the problem, rather it is the fidelity of its implementation and the quality and quantum of the support that is provided. So we also need to review and take heed of the research evidence for what makes for an effective implementation, and review each step towards it from the bottom up. Only when this has been achieved, will we have completed the chain of evidence from special education policy to enhanced student outcomes.

\section{REFERENCES}

Brown, D. (2010). The dodo, the auk and the onyx - and educational psychology? Psychology Aotearoa, 2(1), 12-19.

Clark, P., MacArthur, J., McDonald, T., SimmonsCarlsson, C., \& Caswell, P. (2007). Research project on integrated effective service provision for children and young people with physical disabilities: Two part research project. November, Wellington, New Zealand: Ministry of Education.

Coleman, P. (2005). Behaviour Research Report, Draft 5.1. Unpublished Manuscript.

Coleman, P., \& Pine, T. (2010). The professional practice of educational psychology in New Zealand: Participant perspectives. Psychology Aotearoa, 2(1), 20-25.

Education Review Office. (2004). Evaluation of the Resource Teacher: Behaviour and Learning. Wellington, New Zealand: Education Review Office.

Education Review Office. (2005a). An evaluation of the Ongoing and Reviewable Resourcing Schemes. Wellington, New Zealand: Education Review Office.

Education Review Office. (2005b). An evaluation of the Special Education Grant. Wellington, New Zealand: Education Review Office.

Education Review Office. (2009). Activity centres - an overview. October, Wellington, New Zealand: Education Review Office.

Education Review Office. (2009). Reading and writing in Years 1 and 2. December. Wellington, New Zealand: Education Review Office.

Education Review Office. (2009). Resource Teachers: Learning and Behaviour - An evaluation of cluster management. September, Wellington, New Zealand: Education Review Office. 
Education Review Office. (2010). Good practice in alternative education. September, Wellington, New Zealand: Education Review Office.

Education Review Office. (2010b). Including students with high needs. June, Wellington, New Zealand: Education Review Office.

Elmore, R. F. (2005). School reform from the inside out. Policy, practice and performance. Harvard Education Press.

Gray Matter Research Ltd. (2005). Enhanced Programme Fund Evaluation. June, Wellington, New Zealand: Ministry of Education.

Hornby, G. (2010). The demise of educational psychology in New Zealand: A personal view. Psychology Aotearoa, 2(1), 26-30.

Massey University College of Education. (1999). Monitoring and evaluation of the Special Education 2000 Policy: Summary Report, Phase 1 - 1999. Wellington, New Zealand: Ministry of Education.

Massey University College of Education. (2000). Monitoring and evaluation of the Special Education 2000 Policy: Summary Report of Phase 2 - 2000. Wellington, New Zealand: Ministry of Education.

Massey University College of Education. (2002). Special Education 2000. Monitoring and evaluation of The Policy: Final Report - Phase 3. Wellington New Zealand: Ministry Of Education.

McMenamin, T. (2009). New Zealand Day Special Schools: Changes and challenges under Special Education 2000. New Zealand Review of Education, 18, 183-200.

McMenamin, T., Miller, R., Morton, M., Mutch, C., Nuttall, J., \& Tyler-Merrick, G. (2004). Curriculum policy and Special Education report. March, Wellington, New Zealand: Ministry of Education.

Ministry of Education. (1996). Special Education 2000 Policy. July, Wellington, New Zealand: Ministry of Education.

Ministry of Education. (2006). Evaluation of the Supplementary Learning Support Initiative. Final Report. June, Wellington, New Zealand: Ministry of Education.

Ministry of Education. (2007a). Integrated effective service provision for children and young people with physical disabilities: A Summary of Two Research Projects. November, Wellington, New Zealand: Ministry of Education.

Ministry of Education. (2007b). Resource Teacher: Learning and Behaviour. Policy and Toolkit. Wellington, New Zealand: Ministry of Education.

Ministry of Education. (2007c), The New Zealand curriculum for English-medium teaching and learning in Years 1-13. Wellington: Learning Media Ltd.

Ministry of Education. (2010). The review of Special Education. Public response document. August, Wellington, New Zealand: Ministry of Education.
Report of the Education and Science Committee. (2008). Inquiry into making the schooling system work for every child. February, Wellington, New Zealand: NZ House of Representatives.

Research and Evaluation Unit. (2003). Resource Teachers: Learning and Behaviour - Data on the schools and students they worked with in 2001 - Annual Report 2000. March, Wellington, New Zealand: Ministry of Education.

Research NZ. (2006). Evaluation of the supplementary learning support initiative. June, Wellington, New Zealand: Ministry of Education.

Reynolds, M. C., Wang, M. C. \& Walberg, H. J. (1987). The necessary restructuring of Special Education, Exceptional Children, 53, 391-398.

Sigafoos, J., Moore, D., Brown, D., Green, V. A., O'Rielly, M. F., \& Lancioni, G. S. (2010). Special Education funding reform: A review of impact studies. Australasian Journal of Special Education, 3(1), 17-35.

Special Education Division. (2004). Enhancing Professional Practice in Special Education. Wellington, New Zealand: Ministry of Education.

Timperley, H. S., \& Parr, J. (2010). Weaving evidence, inquiry and standards to build better schools. Wellington, New Zealand: New Zealand Council for Educational Research.

Ward, L., \& Purdie, N., Irving, E., Weston, B., Armstrong, C., King, M., \& Henderson, A. (2009). Survey of Special Education Resourcing. February, Wellington, New Zealand: Ministry of Education.

Webster-Stratton, C. (1999). How to promote children's social and emotional competence. London: Paul Chapman Publishing.

Wylie, C. (2000). Picking up the pieces: Review of special education 2000. He tataritanga mo te matauranga. Wellington, New Zealand: New Zealand Council for Educational Research.

\section{AUTHOR'S PROFILE}

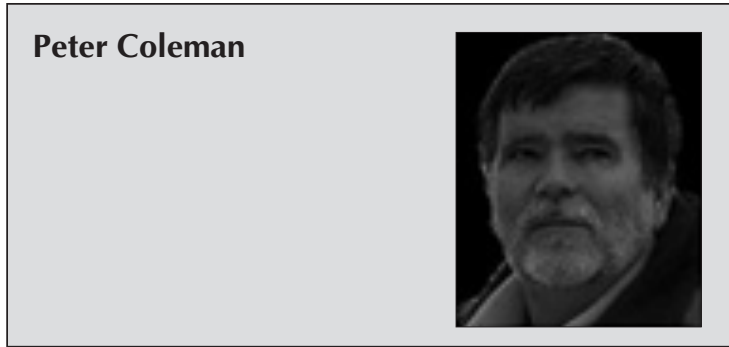

Peter Coleman worked as an educational psychologist within the Department of Education and now Ministry of Education from the early 1970s until 2009, the last 15 years part-time. He then moved into full time private practice specialising in Family Court and child protection work. Peter was Director of Social Issues for the NZPsS and is now PresidentElect.

EMAIL

pcoleman@ihug.co.nz 